GERALDENE PETERS

A PhD researcher on political documentary and activist media in the Department of Film, Television and Media Studies at the University of Auckland

\section{New Left journal of analysis in pursuit of another world}

Red \& Green: The NZ Journal of Left Alternatives 1 (1), edited by Jill Ovens. Auckland, The Red and Green Editorial Board, 2003. 160 pp. ISSN 11761482

$R$ $E D \& G R E E N$ is the latest in a journal tradition engaging with politics and culture in Aotearoa/New Zealand. Immediately, by dint of reference to an early journal article written by Roger Horrocks, the editorial 'voice' of the introduction is conscious of this critical genealogy. The journal $A N D$ was a university based cultural/ literature studies journal produced in the early 1980s, and as both a university professor and a cultural activist, Horrocks is one commentator who continues to be particularly alive to the coexistence of a politics of culture and political economy. His contem-

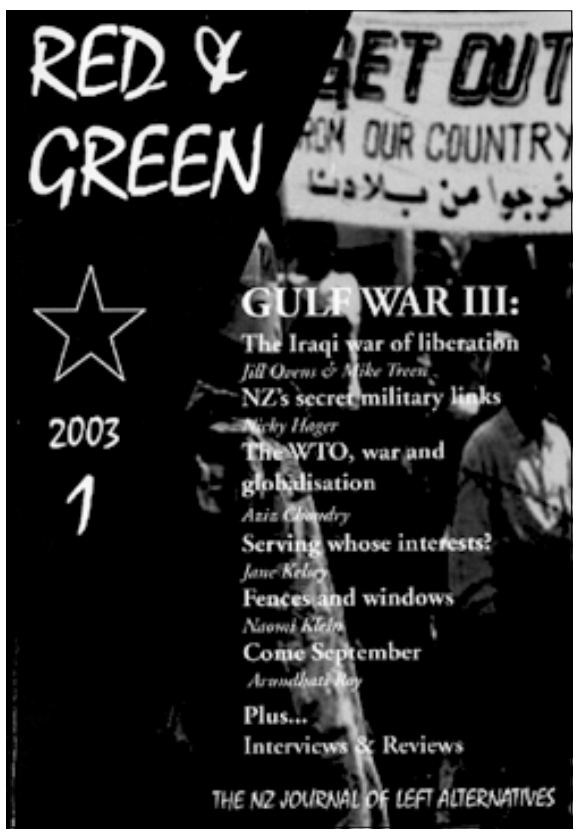

porary, Bruce Jesson - not an academic by choice, but undoubtedly an intellectual - was another. As the editorial infers, within the domains of cultural and political analysis both commentators have been interested to explore the pragmatic method of "replac[ing] overseas theories by the concrete details of local reality" (p 4). Informed by socialist principles, $R \& G$ cannot leave history out of the picture, and editorial choices recurrently signal the journal's place within these strands of pragmatic-theoretical tradition.

In this first issue, the poetics of Arundhati Roy's address spoken on the anniversary of September the $11^{\text {th }}$, 
and the inclusion of media commentary and film reviews, signals the importance of the political dimension of culture. Unlike $A N D$, however, political analysis is the mainstay. This is of no surprise that given all four members of the editorial board are activist intellectuals from the Alliance Party Left, which also contributed seed funding for the journal. Homage to the work of Jesson (during his lifetime, an active member of the Alliance) seems apparent in the topical proximity of the publication to the $N Z$ Political Review (NZPR) - successor to Jesson's The Republican and initially edited by Jesson before his death. Chris Trotter, formerly a part of the New Labour Party/Alliance vanguard and ofttimes comrade of members of the $R \& G$ 's editorial board, inherited the editorship of NZPR and has collegially signalled $N Z P R$ support for $R \& G$ by taking out a back page advertisement. It's certainly to be hoped that the audience for a plurality of Left analysis continues to reveal itself and grow, ensuring that both publications continue.

The NZPR is currently running with the publicity catchphrase 'journalism with attitude' - this, alongside its magazine-like format, 'feature article' focus, distance from overt party allegiances etc. distinguishes it, albeit marginally, from $R \& G$. What does significantly distinguish the two jour- nals is the latter's collective editorial board, academic/activist pitch, and the room allowed for overseas commentary. In these respects, the structure and content of $R \& G$ more closely reflects a mix between the US Monthly Review, and the ethos of both Perry Anderson's New Left Review and Australia's Democratic Socialist publication, Green Left Weekly. $R \& G$ differs also from the $N Z P R$ with its avowal to give space to identity-based issues presumably engaging Socialist and New Left positions in the process of working out what it means to be Left in Aotearoa today.

Race, Gender, Class (RGC), published in Christchurch between 1985 and 1992, was a publication growing out of the identity politics of the time, hence giving particular attention to 'Maaori self-determination, feminism and socialism'. Like $R \& G, R C G$ was collectively edited, positioning itself in distinction from academic journals such as Sites (Massey University, Palmerston North), by focusing on the concrete specifics of homosexual law reform, a Nuclear Free Pacific and the policies of the Labour Government, rather than conceptual questions of individualism, consumerism, national identity, and the future of the State. Consistent with its emphasis on 'Maaori self determination' was an editorial commitment to publishing commentary in Te Reo as well as 
English. In $R \& G$, attention to the Treaty has a place in Bernad Gadd's review of Paul Moon's book The Path to the Treaty of Waitangi, and a stated editorial openness to Maaori Nationalist views. It is still too early though to predict the extent to which Tangata Whenua perspectives will have purchase within an $R \& G$ environment.

Taking Gulf War III as its theme, $R \& G$ can be seen to function as a kind of handbook bringing people up to speed with left arguments on key issues pertaining to the situation in Iraq such as sovereignty; New Zealand foreign policy and the extent of government complicity with the war; background to the operations of New Zealand intelligence services; the lead up to the war; and the role of global capital. Those articles that don't explicitly engage with militarism — such as Jane Kelsey's focus on GATS agendas and Quentin Findlay's propositions on the way forward for the Alliance - shed light on global and local contexts by respectively addressing the machinations of global capital and the place of democratic socialism in Aotearoa. Indeed, the range of articles represent a distillation of local and global currents in Left commentary.

Kelsey's article is an eponymous adaptation of the ARENA (Action, Research \& Education Network of Aotearoa) booklet she produced at the beginning of this year (available online at www.arena.org.nz). Nicky Hager expands on a Sunday Star-Times article he wrote about NZ participation in the war on Afghanistan. In a reprinted article written for Znet, Aziz Choudry - a New Zealander currently researching a $\mathrm{PhD}$ in Canada - draws out the ties between trade liberalisation agendas and increasing militarisation, advocating an alignment between anti-globalisation and peace activists to resist this dynamic.

An abridged version of a Naomi Klein article from her book Fences and Windows, uses figurative language and anecdote to flesh out the structural bones of Kelsey's preceding discussion:

Despite all attempts at privatisation...music, water, seeds, electricity, ideas...have a natural resistance to enclosure... (p 99).

It's of some relevance that Klein's 2001 visit to Aotearoa was sponsored by the Alliance. Roy's address, along with the Research Unit for Political Economy (RUPE) excerpts, bring questions of colonialism back into the mix, rounding off arguments for Iraqi self determination introduced by Jill Ovens and Mike Treen. There are questions of national self expression posed in the introduction, and consistent editorial references (explicit and 
implicit) to Edward Said's notion of 'travelling theories' ( $p p 5,146$ ).

Turning back to history, the first page of the introduction explicitly invokes Marx's socialist vision, foreshadowing the encounters with history in the articles of Keith Locke, John Minto, Roy, the RUPE material, and the oral histories of Robert Reid and Ray Weeber. Appropriately for activist intellectuals, the articles of Roy, Findlay, Choudry and Kelsey end with a provocation to think and act the way forward.

As the editors state, the task is to 'prov(e) that another world is possible' (p 1). In his comprehensive review of On the Left: Essays on Socialism in New Zealand, Len Richards (an $R \& G$ editor) looks forward to the book's sequel. Drawing from Richards' inference, as both a complement to and extension of that sequel, Red \& Green can be seen as an ideal vehicle for keeping that history, its current manifestations and future aspirations in public view (p 9). 